\title{
8
}
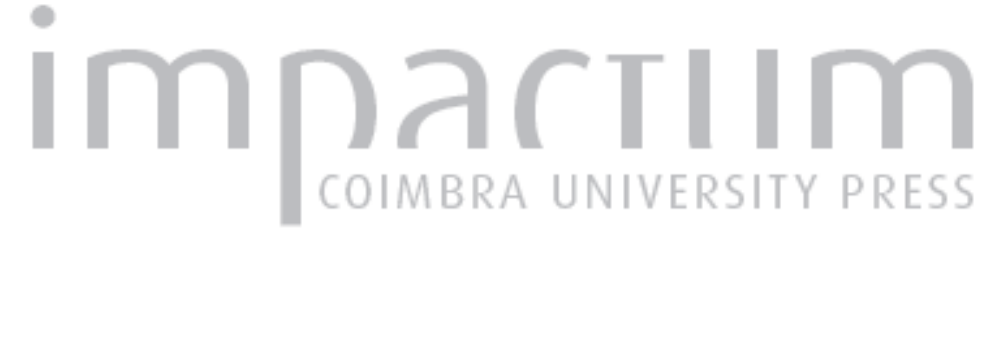

\section{A evolução dos conceitos de cidadania e de nacionalidade no direito internacional e no direito comunitário}

Autor(es): $\quad$ Sachett, Barbara Mourão

Publicado por: Imprensa da Universidade de Coimbra

URL persistente:

URI:http://hdl.handle.net/10316.2/43675

DOI:

DOI:https://doi.org/10.14195/1647-6336_19_1

Accessed : $\quad$ 26-Apr-2023 14:26:04

A navegação consulta e descarregamento dos títulos inseridos nas Bibliotecas Digitais UC Digitalis, UC Pombalina e UC Impactum, pressupõem a aceitação plena e sem reservas dos Termos e Condições de Uso destas Bibliotecas Digitais, disponíveis em https://digitalis.uc.pt/pt-pt/termos.

Conforme exposto nos referidos Termos e Condições de Uso, o descarregamento de títulos de acesso restrito requer uma licença válida de autorização devendo o utilizador aceder ao(s) documento(s) a partir de um endereço de IP da instituição detentora da supramencionada licença.

Ao utilizador é apenas permitido o descarregamento para uso pessoal, pelo que o emprego do(s) título(s) descarregado(s) para outro fim, designadamente comercial, carece de autorização do respetivo autor ou editor da obra.

Na medida em que todas as obras da UC Digitalis se encontram protegidas pelo Código do Direito de Autor e Direitos Conexos e demais legislação aplicável, toda a cópia, parcial ou total, deste documento, nos casos em que é legalmente admitida, deverá conter ou fazer-se acompanhar por este aviso.

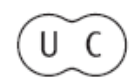


DEBATER

A EUROPA

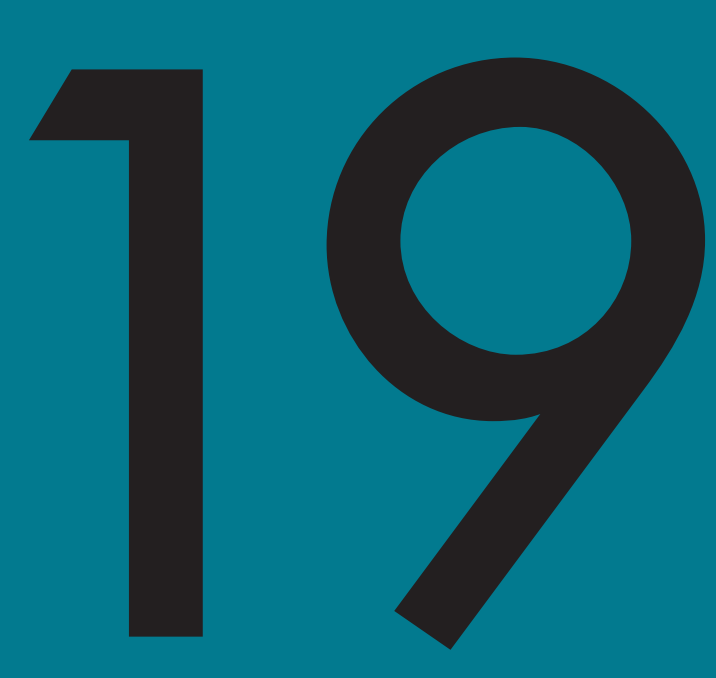

jul-dez 2018

QUE DESAFIOS À CIDADANIA EUROPEIA NO SÉCULO XXI?

WHAT CHALLENGES TO EUROPEAN

CITIZENSHIP IN THE 21ST CENTURY? 


\section{A evolução dos conceitos de cidadania e de nacionalidade no direito internacional e no direito comunitário}

\section{The evolution of the concepts of citizenship and nationality in in- ternational law and community law}

Barbara Mourão Sachett

Mestre em Direito Internacional, Advogada, Professora da Universidade Metodista, pesquisadora do Cedmar - USP e do NETI - USP barbara_mourao@hotmail.com

\section{Resumo}

Este artigo tem por objeto a análise da evolução dos conceitos da nacionalidade e da cidadania no Direito Internacional, nos Direitos Humanos e no Direito Comunitário. Para essa finalidade, serão analisados os principais dispositivos dos tratados sobre a matéria.

Palavras-chave: Cidadania, Nacionalidade, Direito Comunitário, Direitos Humanos, Direito Internacional.

\section{Abstract}

The purpose of this article is to analyze the evolution of the concept of nationality and citizenship in International Law, Human Rights and European Union Law. For this purpose, the main treaty provisions on the subject will be analyzed.

Keywords: Citizenship, Nationality, European Union Law, Human rights, International Law.

\section{Introdução}

Nacionalidade é um vínculo jurídico-político que une uma pessoa física a determinado Estado. Já o conceito de cidadania, é mais amplo, englobando os direitos civis e políticos do indivíduo. 
O Direito Comunitário europeu criou, a partir dos textos das suas convenções do processo de integração, uma nova categoria de cidadania: a cidadania europeia, que está relacionada à União Europeia (organização supranacional) e não aos Estados-membros.

Os tratados de direitos humanos disciplinam a nacionalidade e a cidadania concedendo aos cidadãos, pelo menos na teoria, o status de cidadão universal. São exemplos a Convenção Americana sobre direitos humanos, de 1969, e a A Declaração Universal dos Direitos do Homem, de 1948.

No âmbito do Direito Comunitário, nacionalidade e cidadania são tratadas em vários dispositivos; no Tratado de Roma, de 1957 e no Tratado sobre o funcionamento da União Europeia.

\section{Nacionalidade e cidadania: conceituação no Direito Internacional e Comunitário}

Tradicionalmente, a nacionalidade é considerada um elo entre uma pessoa física e determinado Estado, ligação essa, de natureza política e jurídica. Nos Estados Unidos, a noção de nacionalidade se confunde com a de cidadania, como se pode depreender da análise da Emenda XIV à Constituição americana, onde o termo cidadão tem o mesmo valor que o termo nacional ${ }^{1}$

Nacionalidade e cidadania são conceitos que se inserem em estratos sociais diferentes e, portanto, não devem ser confundidos. A nacionalidade, sobre tradicionalmente implicar a integração de fato das pessoas numa comunidade política (a polis), corresponde a uma noção ordinariamente integrada em temática sociológica: a sociologia da vivência (convivência) humana na polis, um modo de pertinência a uma sociedade política organizada em que ela, a cidadania, consiste. Nesse sentido, a nacionalidade envolve a noção de pertinência, o fato de pertencer alguém a uma totalidade, que é o Estado nação. É sob esse aspecto um conceito sociológico².

Não obstante, apesar de apresentar muitos pontos de semelhança entre si, grande parte dos doutrinadores faz a distinção entre nacionalidade e cidadania, principalmente no tocante ao alcance dos direitos concedidos, entre outros elementos.

O conceito de cidadania originou-se no século XVIII com o surgimento dos direitos civis, no bojo da ruptura com o Antigo Regime absolutista e do ápice do Iluminismo. O ser humano passa a ser detentor do status de cidadão, tendo a liberdade e a igualda-

1 DOLINGER, M; TIBURCIO, C.- Direito Internacional Privado. $13^{\mathrm{a}}$ ed. Rio de Janeiro: Forense, 2017. 117 p. ISBN 978-85-309-7319-3.

2 BORGES, José Souto Maior- Curso de Direito Comunitário. 2a ed. São Paulo: Saraiva, 2009. 564 p. ISBN 978-85-020693-7. 
de asseguradas por um mínimo de normas jurídicas, entretanto, o desenvolvimento do conteúdo da cidadania não ocorreu sem imprecisão: identificado com uma gama muito variada de princípios, desde a aquisição ou perda de nacionalidade até a obtenção de direitos políticos, o que contribuiu para a para a utilização equivocada do termo nos mais variados contextos ${ }^{3}$.

Nacionalidade é matéria tratada em direito interno, mas a partir da década de 30 do século XX, foram ratificadas várias convenções internacionais sobre o tema, o que, por si, não ocasionou a internacionalização do instituto, no entanto, alguns dos seus princípios passaram a ser estudados pelo Direito Internacional ${ }^{4}$.

Quanto à atribuição da nacionalidade à pessoa física, existe a previsão de dois critérios: o ius sanguinis e o ius soli. O primeiro, mais tradicional, foi aplicado durante a Antiguidade, e, atualmente, na Europa e em vários países colonizadores: por meio do ius sanguinis, a nacionalidade é atribuída por meio da filiação. Já o ius soli foi predominante na Idade Média, sendo aplicado atualmente em países colonizados. Por meio desse critério, a nacionalidade é atribuída pelo Estado onde o indivíduo nasceu.

Quanto aos tipos, a nacionalidade pode ser originária e adquirida (ou derivada). A originária é aquela que o indivíduo adquire ao nascer ou em virtude de obtenção de dupla nacionalidade, já a adquirida (ou derivada), é aquela advinda de processo de naturalização. Deve-se mencionar, também, que alguns países aplicam o sistema misto, no qual se fundem características dos dois tipos: a originária e a adquirida ou derivada ${ }^{5}$.

A cidadania europeia, e todos os direitos e deveres advindos com a aquisição da mesma, característica do final do século XX, é o vínculo jurídico-político que se criou entre a Europa e seus cidadãos a partir do processo de integração europeia.

Uma das grandes novidades creditadas ao Direito Comunitário na Europa, consiste no tratamento jurídico conferido pelo mesmo à cidadania, que não está mais juridicamente vinculada somente aos Estados nacionais, mas também se confirma no âmbito comunitário ${ }^{6}$. Qualquer cidadão de um Estado-membro da União Europeia, é, automaticamente, cidadão europeu.

3 MAZZUOLI, Valério - Curso de Direito Internacional Público. 39ªed São Paulo: RT, 2015. 738 p. ISBN 978-85-203-5806-1.

4 MELLO, Celso D. de Albuquerque. - Curso de Direito Internacional Público. 15 a ed. Rio de Janeiro: Renovar, 2004. 992 p. ISBN 85-7147-417-6.

5 De acordo com o artigo 12, I, da Constituição Federal brasileira de 1988, o Brasil aplica o ius soli, e o ius sanguinis em determinadas situações:" São brasileiros natos: a) os nascidos na República Federativa do Brasil, ainda que de pais estrangeiros, desde que estes não estejam a serviço de seu país; b) os nascidos no estrangeiro, de pai brasileiro ou mãe brasileira, desde que qualquer deles esteja a serviço da República Federativa do Brasil; c) os nascidos no estrangeiro de pai brasileiro ou de mãe brasileira, desde que sejam registrados em repartição brasileira competente ou venham a residir na República Federativa do Brasil e optem, em qualquer tempo, depois de atingida a maioridade, pela nacionalidade brasileira".

6 BORGES, José Souto Maior- Curso de Direito Comunitário, p. 565. 
Apesar de sua grandeza e inovação, o projeto de cidadania europeia, desenvolvido pelo Direito Comunitário, não restou imune a críticas e a problemas de ordens práticas quanto à concessão efetiva de direitos aos cidadãos europeus:

A ausência de um vínculo jurídico-político direto entre os cidadãos e a União, bem como a distância dos elementos que diferenciam a noção legal-formal de cidadania de acordo com a posição jurídica do sujeito - portador de direitos e deveres -, criam uma problemática concernente ao status civitatis nacional. É notório que, pela primeira vez na história, com a instituição da cidadania europeia, pertencer a um território, a uma comunidade e a uma cultura definida nos limites nacionais passou ao controle de uma entidade supranacional: a União Europeia. Como veremos, porém, tal situação gera um intenso debate na doutrina?.

No Direito Comunitário inexistem deveres expressos em relação ao cumprimento de obrigações comuns para além das fronteiras estatais, o que, por sua vez, em contraposição aos inúmeros direitos elencados nas fontes originárias e derivadas do ordenamento comunitário, fragiliza e gera uma sensação de descrença na efetividade do status de cidadão europeu ${ }^{8}$.

A seguir será analisado como se dá o tratamento do direito à nacionalidade é à cidadania nos tratados de direitos humanos.

\section{2. $\mathrm{O}$ direito à nacionalidade e cidadania nos Tratados de Direitos Humanos}

Em sede de direitos humanos há uma série de convenções internacionais que disciplinam e protegem o instituto da nacionalidade.

A Declaração Universal dos Direitos do Homem, de 1948, em seu artigo 15, parágrafos 1 e 2, estabelece que "todo homem tem direito a uma nacionalidade" e que "ninguém será arbitrariamente privado de sua nacionalidade, nem do direito de mudar de nacionalidade" .

No âmbito do sistema de proteção americana de direitos humanos, a Convenção Americana sobre direitos humanos, assinada em São José da Costa Rica, em 1969, em seu artigo 20, disciplina a matéria em seus parágrafos 1 a 3.

7 MOURA, Aline Beltrame de. - CIDADANIA EUROPEIA: Uma Verdadeira e Própria Cidadania? Revista Direito em Debate. v. 18, n. 32. (2013) [Consult. 24 de Fevereiro de 2018]. Disponível em www: <https://www.revistas.unijui.edu.br/index.php/revistadireitoemdebate/article/view/629>

ISSN 2176-6622.

8 MOURA, Aline Beltrame de.- CIDADANIA EUROPEIA: Uma Verdadeira e Própria Cidadania?, p. 13.

9 Declaração Universal dos Direitos Humanos, disponível em: < https://www.unicef.org/brazil/pt/ resources_10133.htm>, Consult. em 25 de Fevereiro de 2018. 
1.Toda pessoa tem direito a uma nacionalidade.

2.Toda pessoa tem direito à nacionalidade do Estado em cujo território houver nascido, se não tiver direito a outra.

3.A ninguém se deve privar arbitrariamente de sua nacionalidade nem do direito de mudá-la ${ }^{10}$.

O Direito Internacional preconiza dois princípios contraditórios acerca do instituto da nacionalidade e o da liberdade de circulação; pode-se mencionar, a título exemplificativo, o artigo 12, parágrafo 2, do Pacto Internacional sobre Direitos Civis e Políticos ${ }^{11}$, adotado e aberto à assinatura, ratificação e adesão pela Assembleia Geral das Nações Unidas por meio da Resolução 2200-A (XXI), de 16 de Dezembro de 1966, estabelecendo que a "toda pessoa é assegurado o direito de deixar qualquer país, inclusive o próprio, e a ele regressar". Ao mesmo tempo, encontra-se no artigo 12, parágrafo 3, restrições ao direito estabelecido no parágrafo 2 quando as mesmas sejam previstas na lei e justificadamente necessárias para proteger a segurança nacional, a ordem pública, a saúde ou a moral pública, e os direitos e liberdades de terceiros ${ }^{12}$.

Na mesma linha, é digo de nota a sistemática sobre nacionalidade e liberdade de circulação de pessoas estabelecida por meio da Convenção para os Direitos do Homem e das Liberdades Fundamentais do Conselho da Europa, no Protocolo n ${ }^{\circ} 4$. Em seu artigo $2^{\circ}$, parágrafo 1, é reconhecido o direito a "qualquer pessoa que se encontra em situação regular em território de um Estado ter o direito a nele circular livremente e a escolher livremente a sua residência"13. Por outro lado, nos parágrafos 3 e 4, são previstas determinadas restrições aos direitos assegurados nos parágrafos 1 e $2^{14}$.

3. O exercício destes direitos não pode ser objeto de outras restrições senão as que, previstas pela lei, constituem providências necessárias, numa sociedade democrática, para a segurança nacional, a segurança pública, a manutenção da ordem pública, a

10 Convenção Americana sobre Direitos Humanos, disponível em: <https://www.cidh.oas.org/basicos/portugues/c.convencao_americana.htm>, Consult. em 25 de Fevereiro de 2018.

11 Pacto Internacional de Direitos Civis e Políticos, disponível em: <http://www.refugiados.net/ cid_virtual_bkup/asilo2/2pidcp.html>, Consult. em 25 de Fevereiro de 2018.

12 GARCIA, P.P. Márcio. - Estrangeiro e Migrante no ordenamento jurídico brasileiro. In RAMOS, André de Carvalho.- Direito Internacional Privado. Questões Controvertidas.- Belo Horizonte: Arraes Editores, 2016. ISBN 978-85-8238-205-9.

13 Protocolo $\mathrm{n}^{\circ} 4$ da Convenção para os Direitos do Homem e das Liberdades Fundamentais do Conselho da Europa, disponível em: $<$ http://www.echr.coe.int/Documents/Convention_POR.pdf $>$, Consult. em 25 de Fevereiro de 2018.

14 GARCIA, P.P. Márcio, - Estrangeiro e Migrante no Ordenamento Jurídico brasileiro, p.153. 
prevenção de infrações penais, a proteção da saúde ou da moral ou a salvaguarda dos direitos e liberdades de terceiros.

4. Os direitos reconhecidos no parágrafo 1 podem igualmente, em certas zonas determinadas, ser objeto de restrições que, previstas pela lei, se justifiquem pelo interesse público numa sociedade democrática ${ }^{15}$.

Em relação ao instituto da cidadania e sua inserção nos mecanismos internacionais de proteção aos direitos humanos, a já citada Declaração Universal dos Direitos Humanos ${ }^{16}$ , em seu artigo $1^{\circ}$, preconiza que: "todos os seres humanos nascem livres e iguais em dignidade e direitos. São dotados de razão e consciência e devem agir em relação uns aos outros com espírito de fraternidade".

O sistema internacional de proteção aos direitos humanos não faz distinção entre nacional e estrangeiro, e desde o final de Segunda Guerra Mundial, quando o mesmo foi desenvolvido, o grande objetivo foi proteger a pessoa física com a criação de um complexo de normas e dotando-a, indiretamente, do status de cidadã universal.

Não obstante, há grandes desafios, até os dias atuais, para a implementação dessa proteção normativa e a concessão da cidadania universal:

Mas, na prática, constata-se que não são respeitados os direitos humanos da grande maioria dos migrantes. Num mundo de 200 milhões de migrantes internacionais, esse dado preocupa. As imensas desigualdades no desenvolvimento entre as regiões do planeta e a ausência de dignidade humana são as grandes causas do deslocamento de significativos fluxos de migrantes nos dias atuais. As pessoas procuram sua cidadania em outros lugares, onde supõem que, por serem mais desenvolvidos econômica e socialmente a encontrarão, deparando-se muitas vezes com o preconceito e a discriminação ${ }^{17}$.

O direito à cidadania universal e a todos os direitos a ela concedidos, independe das soberanias estatais e dos Estados e deve ser garantido por meio do sistema de proteção internacional aos direitos humanos para além da teoria.

15 Protocolo $\mathrm{n}^{\circ} 4$ da Convenção para os Direitos do Homem e das Liberdades Fundamentais do Conselho da Europa, disponível em: <http://www.echr.coe.int/Documents/Convention_POR.pdf>, Consult. em 25 de Fevereiro de 2018.

16 Declaração Universal dos Direitos Humanos, disponível em: < https://www.unicef.org/brazil/pt/ resources_10133.htm>, Consult. em 25 de Fevereiro de 2018.

17 FARENA, Maritza Natalia Ferreti Cisneros. - Por uma cidadania universal. Os direitos humanos dos migrantes numa perspectiva cosmopolita- Jura Gentium, Rivista di filosofia del diritto internazionale e della politica globale (2009). [Consult. em 25 de Fevereiro de 2018]. Disponível em: <http://www.juragentium.org/topics/migrant/pt/cosmopol.htm>. ISSN1826-8269. 


\section{O conceito de nacionalidade e cidadania no Tratado de Roma e no Tratado de Funcionamento da União Europeia}

O tratado de Roma, de 1957, assinado em 1957 pela França, Bélgica, Holanda, Alemanha, Luxemburgo e Itália, teve sua denominação alterada para "Tratado sobre o funcionamento da União Europeia".

O termo cidadania origina-se do latim civitas, e significa "cidade", o que, por sua vez, estabelece que determinado indivíduo pertence a uma comunidade politicamente articulada que lhe atribui um conjunto de direitos e obrigações ${ }^{18}$.

A grande originalidade do conceito de cidadania europeia é o fato da mesma não estar vinculada a um Estado-membro, mas a uma instituição supranacional; a União Europeia.

O tratado de Roma, de 1957, anteriormente à consolidação, em seu artigo 17, estabelecia que, para obter a cidadania europeia, o indivíduo deve ser nacional de um Estado-membro.

Esse dispositivo tem função insigne: constitui o centro normativo de imputação dos direitos e deveres, atribuídos a todos os nacionais da União. Esses direitos e deveres são todos inerentes à cidadania, como instituída no Tratado $\mathrm{CE}^{19}$.

O cidadão europeu é titular de direitos e obrigações originados do direito comunitário e não do direito nacional, ou seja, a cidadania não é concedida pelo Estado-nação.

A cidadania, na sua configuração tradicional, sempre esteve vinculada à nacionalidade, o que implicava não só a pertinência a um Estado, mas também a sua circunscrição a esse Estado, sem excluir a possibilidade de mais de uma nacionalidade. Nesse sentido tradicional, que a cidadania europeia altera e largamente ultrapassa, ser cidadão é ser titular de direitos e obrigações na órbita política do Estado-nação, ou seja, ser nacional de um determinado Estado. Também aí dá-se um bouleversement (abalo) do conceito de cidadania, reservado exclusivamente aos Estados, em sua caracterização tradicional ${ }^{20}$.

O tratado de Roma, estabelecia, ainda, a proibição de discriminação em razão da nacionalidade, ao dispor que a "livre circulação suporá a abolição de toda discrimina-

18 História da cidadania europeia, disponível em: <http://www.eurocid.pt/pls/wsd/wsdwcot0. detalhe?p_cot_id=1917>, Consult. em 25 de Fevereiro de 2018.

19 BORGES, José Souto Maior- Curso de Direito Comunitário. 2a ed. São Paulo: Saraiva, 2009. 565 p. ISBN 978-85-020693-7.

20 BORGES, José Souto Maior- Curso de Direito Comunitário. 2ª ed. São Paulo: Saraiva, 2009. 568 p. ISBN 978-85-020693-7. 
ção em razão da nacionalidade dos trabalhadores dos Estados-membros, no que concerne ao emprego, à remuneração e às demais condições de trabalho" ${ }^{21}$.

O Tratado sobre o funcionamento da União Europeia, assinado em 2007 pelos Estados-membros da União Europeia, consolidou o texto de vários tratados negociados anteriormente.

Portanto, a União Europeia de nossos dias tem sua regência determinada por vários instrumentos jurídicos: o Tratado de Lisboa propriamente dito e, com as alterações dele decorrentes, o Tratado da União Europeia e o Tratado sobre o Funcionamento da União Europeia. Trata-se, como se nota, de um modelo bastante avançado de integração, superior até mesmo ao modelo confederativo ${ }^{22}$.

A cidadania é tratada no artigo 20, parágrafo 1.0 do Tratado sobre o funcionamento da União Europeia:

1. É instituída a cidadania da União. É cidadão da União qualquer pessoa que tenha a nacionalidade de um Estado-Membro. A cidadania da União acresce à cidadania nacional e não a substitui ${ }^{23}$.

Por sua vez, os direitos inerentes à cidadania estão previstos no Capítulo V da Carta dos Direitos Fundamentais, e são os seguintes: direito de eleger e ser eleito nas eleições para o Parlamento Europeu; direito de eleger e ser eleito nas eleições municipais; direito a uma boa administração; direito de acesso a documentos; direito de apresentar petições ao Provedor de Justiça; direito de petição ao Parlamento Europeu; liberdade de circulação e permanência e proteção diplomática e consular ${ }^{24}$.

Os tratados da União Europeia, de uma maneira geral, disciplinam a matéria da cidadania europeia garantindo aos cidadãos europeus um mínimo de direitos civis e políticos e um dos maiores desafios no processo de integração europeu consiste justamente na manutenção desses direitos de cidadania em tempos de ruptura e incertezas políticas, sociais e econômicas.

21 Tratado de Roma, disponível em: <http://eur-lex.europa.eu/legal-content/PT/ TXT/?uri=LEGISSUM\%3Aa10000> , Consult. em 25 de Fevereiro de 2018.

22 MAZZUOLI, Valério de Oliveira. - Curso de Direito Internacional Público-, p.709.

23 Tratado sobre o funcionamento da União Europeia, disponível em: $<$ https://europa.eu/europeanunion/sites/europaeu/files/eu_citizenship/consolidated-treaties_pt.pdf\#page=57>, Consult. em $25 \mathrm{de} \mathrm{Fe-}$ vereiro de 2018.

24 Carta dos Direitos Fundamentais, disponível em: <http://www.europarl.europa.eu/charter/pdf/ text_pt.pdf >, Consult. em 25 de Fevereiro de 2018. 


\section{Considerações finais}

O direito à cidadania sempre foi garantido em sede de direitos humanos, nas principais convenções sobre a matéria, principalmente após o fim da Segunda Guerra Mundial.

A nacionalidade e a cidadania são institutos que se complementam. A concessão de direitos civis e políticos aos cidadãos europeus sempre foi um grande diferencial e um atrativo no processo de integração na Europa.

Desde o Tratado de Roma, de 1957, de uma forma incipiente, até a negociação do Tratado sobre o funcionamento da União Europeia, em 2007, a concessão de direitos advindos da cidadania é uma constante na identidade do povo europeu e contribui sobremaneira no desenvolvimento do processo de integração.

O grande desafio para a Europa, no século XXI, será além de manter o mesmo ritmo de crescimento e desenvolvimento no processo de integração, a manutenção dos direitos de cidadania em tempos de ruptura e incertezas políticas, sociais e econômicas

\section{Referências bibliográficas}

BORGES, José Souto Maior- Curso de Direito Comunitário. $2^{\mathrm{a}}$ ed. São Paulo: Saraiva, 2009. 564 p. ISBN 978-85-020693-7.

Carta dos Direitos Fundamentais, disponível em: <http://www.europarl.europa.eu/ charter/pdf/text_pt.pdf >, Consult. em 25 de Fevereiro de 2018.

COLOMBO, Alessandro - The principle of Subsidiarity and European CitizenshipMilano. ed: Vita e Pensiero, 2004[ Consult.24 de Fevereiro de 2018]. Disponível em: $<$ https://books.google.com.br/books?id=foo4zvpwAIYC\&pg=PA24\&lpg=PA24\&dq=europ ean+citizenship\&source $=$ bl\&ots $=$ fQU4KqjImq\&sig $=$ Ab-4WP2Wkz8xWVAfIw0gTXL PwRY\&hl=en\&sa $=X \& v e d=0 a h U K E w j \_w O i L h 7 \_Z A h W B h p A K H S Y 8 A j A 4 P B D o A Q h F$ MAA\#v $=$ onepage $\& \mathrm{q}=$ european $\% 20$ citizenship\&f $=$ false $>$

ISBN 88-343-5014-6

Convenção Americana sobre Direitos Humanos, disponível em: <https://www.cidh. oas.org/basicos/portugues/c.convencao_americana.htm>, Consult. em 25 de Fevereiro de 2018.

Declaração Universal dos Direitos Humanos, disponível em: $<$ https://www.unicef.org/ brazil/pt/resources_10133.htm>, Consult. em 25 de Fevereiro de 2018.

DOLINGER, M; TIBURCIO, C.- Direito Internacional Privado. $39^{\mathrm{a}}$ ed. Rio de Janeiro: Forense, 2017. 117 p. ISBN 978-85-309-7319-3.

FARENA, Maritza Natalia Ferreti Cisneros. - Por uma cidadania universal. Os direitos humanos dos migrantes numa perspectiva cosmopolita- Jura Gentium, Rivista di filosofia del diritto internazionale e della politica globale (2009). [Consult. em 25 de Fevereiro de 2018]. Disponível em: <http://www.juragentium.org/topics/migrant/pt/cosmopol.htm>. ISSN1826-8269. 
GARCIA, P.P. Márcio. - Estrangeiro e Migrante no ordenamento jurídico brasileiro. In RAMOS, André de Carvalho.- Direito Internacional Privado. Questões Controvertidas.Belo Horizonte: Arraes Editores, 2016. ISBN 978-85-8238-205-9.

História da cidadania europeia, disponível em: $<$ http://www.eurocid.pt/pls/wsd/wsdwcot0.detalhe?p_cot_id=1917>, Consult. em 25 de Fevereiro de 2018.

ISIS, E.F; SAWARD, M. - Enacting European Citizenship- New York: Cambridge University Press, 2013 [Consult. 24 de Fevereiro de 2018]. Disponível em: <https://books. google.com.br/books?id=Gx5n-LfcuuwC\&pg=PA45\&lpg=PA45\&dq=european+citizens hip\& source $=$ bl\&ots $=$ aZgNGqFPhZ\&sig $=$ Dx8u20CCMS2zCnzP9rYfnYyEBIU\&hl=en\& $\mathrm{sa}=\mathrm{X} \& \mathrm{ved}=0 \mathrm{ahUKEwjD1L2Z1b \_ ZAhXBGpAKHfFTAS84PBDoAQhsMAc \# v= \text {onepag }}$ $\mathrm{e} \& \mathrm{q}=$ european $\% 20$ citizenship\& $\mathrm{f}=$ false $>$.

ISBN 978-107-03396-2

LAFER, Celso. - A reconstrução dos direitos humanos- São Paulo: Companhia das Letras, 2001. 35 p. ISBN 85-7164-011-4.

MAZZUOLI, Valério - Curso de Direito Internacional Público. $9^{\mathrm{a}}$ ed. São Paulo: RT, 2015. 738 p. ISBN 978-85-203-5806-1.

MELLO, Celso D. de Albuquerque. - Curso de Direito Internacional Público. $15^{\mathrm{a}} \mathrm{ed}$. Rio de Janeiro: Renovar, 2004. 992 p. ISBN 85-7147-417-6.

MOURA, Aline Beltrame de. - CIDADANIA EUROPEIA: Uma Verdadeira e Própria Cidadania? Revista Direito em Debate. v. 18, n. 32. (2013) [Consult. 24 de Fevereiro de 2018]. Disponível em www: <https://www.revistas.unijui.edu.br/index.php/revistadireitoemdebate/article/view/629>

ISSN 2176-6622.

Pacto Internacional de Direitos Civis e Políticos, disponível em: $<$ http://www.refugiados.net/cid_virtual_bkup/asilo2/2pidcp.html>, Consult. em 25 de Fevereiro de 2018.

PIOVESAN, Flávia- Direitos humanos e Justiça internacional- $6^{\text {a }}$ ed. São Paulo: Saraiva, 2015. ISBN 978-85-02-61998-2

Protocolo $n^{\circ} 4$ da Convenção para os Direitos do Homem e das Liberdades Fundamentais do Conselho da Europa, disponível em: $<$ http://www.echr.coe.int/Documents/Convention_POR.pdf $>$, Consult. em 25 de Fevereiro de 2018.

Tratado de Roma, disponível em: <http://eur-lex.europa.eu/legal-content/PT/ TXT/?uri=LEGISSUM\%3Aa10000> , Consult. em 25 de Fevereiro de 2018.

Tratado sobre o funcionamento da União Europeia, disponível em: <https:/europa.eu/european-union/sites/europaeu/files/eu_citizenship/consolidated-treaties pt.pdf\#page= 57>, Consult. em 25 de Fevereiro de 2018 . 